\section{La construcción teórica de los movimientos sociales en Chile: El movimiento de pobladores, entre la Sociología y la Historia Social ${ }^{*}$}

The theoretical construction of social movements in Chile: The pobladores movement between Sociology and Social History

Mónica Iglesias-VÁZQUeZ ${ }^{* *}$

\section{Resumen}

Este artículo analiza la confrontación entre una perspectiva sociológica que negó la existencia del movimiento de pobladores y la corriente de la Nueva Historia que reconoció el protagonismo popular en la lucha contra la Dictadura y el potencial democratizador de las acciones desplegadas por los pobladores. La hipótesis que defiende es que la construcción teórica del movimiento social implica una forma de comprender los actores sociales y la transformación social que tiene efectos -en determinado nivel- sobre los propios procesos de lucha. De esta manera, la negación del movimiento de pobladores, como conclusión teórica, justificó la exclusión política de los pobladores y de sus reivindicaciones del diseño de la "transición a la democracia", mientras que la afirmación del protagonismo popular buscó potenciar las posibilidades democratizadoras contenidas en las luchas poblacionales.

Palabras clave: Movimientos sociales, movimiento de pobladores, sociología, historia social.

\begin{abstract}
This article analyzes the confrontation between a sociological perspective which denied the existence of the pobladores movement and the New History stream which recognized the popular role in the fight against the dictatorship and the democratizing potential of the actions deployed by the pobladores. The hypothesis defended is that the theoretical construction of the social movement involves a way of understanding the social actors and social transformation that has
\end{abstract}


effects -at a certain level- on the own processes of struggle. Thus, the denial of the pobladores movement, as a theoretical conclusion, justified the political exclusion of the pobladores and their claims from the design of the transition to "democracy", while the assertion of the popular role sought to enhance the democratizing possibilities contained in the pobladores' struggles.

Key words: Social movements, pobladores' movement, sociology, social history.

\section{El estudio de los pobladores y la performatividad de la ciencia social}

Los sectores populares han desempeñado un papel fundamental en los grandes procesos de transformación social y política del siglo $\mathrm{XX}$, aunque no siempre despertaron un interés científico acorde con dicho protagonismo (Garcés, 2004: 14). Quizás por eso sorprenda la atención que recibieron los pobladores en la década de los ochenta del siglo pasado, cuando su estudio se constituyó en una de las problemáticas centrales de las ciencias sociales chilenas, promoviendo y moldeando los debates sobre movimientos sociales. La emergencia de protestas contra la Dictadura, desde 1983, con carácter abierto y generalizado pero con significativa presencia de pobladores jóvenes, estimuló la discusión acerca del estatuto teórico de esas formas de rebelión. La preocupación sociológica y política giró, entonces, en torno a la consideración de su potencial democratizador, de cara a la salida de la Dictadura; y, en relación con ello, las investigaciones indagaron acerca de la posibilidad de caracterizar los eventos de protesta y movilización, y las experiencias de organización comunitaria desarrolladas por los sectores populares, como "verdaderos" movimientos sociales. Es decir, la inquietud teórica fundamental se expresó en la pregunta: "¿Se constituyen movimientos sociales en Chile?" (Campero, 1986). ${ }^{1}$

El estudio de los pobladores convocó a diversos científicos sociales en varias instituciones, pero uno de los debates más trascendentes se llevó a cabo en SUR, Centro de Estudios Sociales y Educación, uno de los muchos centros académicos independientes fundados durante el período dictatorial como reacción a la clausura de centros universitarios, cierre de disciplinas, censura de planes de estudio y persecución de científicos sociales, en definitiva, a la jibarización e intervención de las ciencias sociales. La importancia de aquella discusión radica en dos cuestiones: de un lado, los sociólogos que se preocuparon sistemáticamente de la materia (Eugenio Tironi, Vicente Espinoza, Guillermo Campero, François Dubet) llegaron a la conclusión de que los pobladores no constituían un movimiento social y, más aun, que sus tendencias al comunitarismo y a la violencia explosiva -de acuerdo con sus "hallazgos"- los hacían más bien acreedores del rótulo de antimovimiento social, esto es, una forma de acción colectiva involucionista y reaccionaria (Touraine, 2000: 122); de otro, la presencia en esa misma institución del historiador Gabriel Salazar, cuya comprensión de las acciones poblacionales se situaba en las antípodas de aquellas proposiciones, propició la confrontación abierta y franca de posturas intelectuales. Acorto plazo, lanegación sociológica

La tensión entre "viejos" y "nuevos" movimientos sociales que constaron las ciencias sociales en la década de los ochenta, ante la emergencia de protestas y movilizaciones de sectores tradicionalmente excluidos de la política, fue abordada, en una perspectiva latinoamericana, en Camacho y Menjívar (1989). Para una visión general de los movimientos sociales durante la Dictadura véase, Guillaudat y Mouterde (1998). 
se impuso por sobre la concepción afirmativa de la historia social; con todo, al correr del tiempo, la perspectiva salazariana -que es la expresión más diáfana de la renovación historiográfica que tuvo lugar en los años ochenta y de la corriente de la Nueva Historia-, parece haber ganado presencia en el debate académico y profundidad sociopolítica. En todo caso, fue esa coyuntura una de las experiencias intelectuales más fecundas para la construcción de los movimientos sociales como objeto (o sujeto) de estudio; por eso, volver sobre ella resulta imprescindible para comprender la relación recíproca entre la sociedad y las ciencias sociales.

Precisamente, el concepto de performatividad de la ciencia social alude a los efectos que las propias teorizaciones de los investigadores tienen sobre sus objetos/sujetos de estudio, y presupone que el científico social no sólo describe e interpreta una determinada realidad sino que, con su trabajo, contribuye a dar forma a esa realidad, esto es, a construirla, no sólo teórica sino también prácticamente. ${ }^{2}$ Como las nociones de "profecía autocumplida" y "profecía autonegada" (Merton, 1964), ${ }^{3}$ la idea de performatividad permite comprender que la construcción teórica de una realidad social contribuye a que dicha realidad sea percibida en consonancia con aquella teoría y que los sujetos actúen consecuentemente, detonando comportamientos acordes o disconformes. De ahí la importancia de la ciencia y de la construcción de visiones del mundo en la lucha política.

Sobre la noción de performatividad véase Butler (2004), quien la ha aplicado al concepto de "género", desvelando el carácter socialmente compartido e históricamente construido del mismo.

3 La primera se refiere al hecho de que una definición en principio "falsa" suscita un nuevo comportamiento que convierte en "verdadera" aquella caracterización; la segunda opera a la inversa, cuando una nueva conducta acaba falseando una definición inicialmente cierta.
En este trabajo revisamos críticamente ese cruce de miradas entre la sociología y la historia social en su labor de construcción teórica de los movimientos sociales, destacando los presupuestos epistemológicos que han guiado sus respectivos exámenes. La hipótesis que sostenemos es que la construcción teórica del movimiento social implica una forma de comprender los actores sociales y la transformación social que tiene efectos -en determinado nivel- sobre los propios procesos de lucha. De esta manera, la negación del movimiento de pobladores, como conclusión teórica, justificó la exclusión política de los pobladores y de sus reivindicaciones del diseño de la "transición a la democracia", mientras que la afirmación del protagonismo popular que realizó la Nueva Historia buscó potenciar las posibilidades democratizadoras contenidas en las luchas poblacionales. Para desarrollar este argumento presentamos, en primer lugar, una caracterización de las acciones de los pobladores que propiciaron el debate académico; a continuación, exponemos las líneas fundamentales de la perspectiva sociológica negacionista; en tercer lugar, esbozamos la mirada afirmativa de la historia social (centrada, esencialmente, en los trabajos de Salazar). Por último, delineamos algunas de las principales conclusiones que arroja esta confrontación de perspectivas teóricas de cara a los desafíos del presente.

\section{Los pobladores en la lucha contra la Dictadura}

Los sectores populares echaron a andar diversas iniciativas para resistir la cruenta represión militar y los efectos devastadores de las políticas neoliberales implementadas 
tras el golpe de Estado. Para hacer frente a sus necesidades cotidianas, dieron vida -muy a menudo al amparo de la Iglesia y con el apoyo de diversos profesionales- a múltiples organizaciones: comprando juntos, huertos familiares, ollas comunes, grupos de ahorro, círculos de salud, comités de deudores y de sin casa, y un largo etcétera de propuestas populares que configuraron una "nueva economía popular solidaria" (Razeto 1986). ${ }^{4}$ A pesar de la heterogeneidad y de la inestabilidad que caracterizaron a este entramado comunitario en sus manifestaciones concretas, Luis Razeto identificó algunos rasgos comunes en las organizaciones económicas populares, entre los que sobresalen su carácter (tendencialmente) participativo, democrático, autogestionario y autónomo, y el predominio de relaciones que fomentaban la solidaridad, la cooperación y la ayuda mutua. La radicalidad de ese esfuerzo colectivo sustentó una lectura de dicho proceso en términos de una sutura social, de una "recomposición de las solidaridades sociales" (Valdés 1986). A la par de la satisfacción de las necesidades inmediatas, los pobladores reconstruyeron la comunidad como un territorio de autoafirmación y de resistencia, que contenía los gérmenes de relaciones sociales alternativas al individualismo y al autoritarismo propios del modelo económico y político impuesto por la Dictadura. Sin embargo, otros académicos destacaron el carácter transitorio y ensimismado de dichas experiencias, proponiendo una interpretación más pesimista

Razeto establece una tipología para clasificar estas experiencias organizacionales: talleres laborales, organizaciones de cesantes, organizaciones para el consumo básico, organizaciones para problemas habitacionales y otras organizaciones poblacionales de servicios. Además, los pobladores formaron parte de organizaciones de familiares de presos políticos y de detenidos desaparecidos, de peñas folklóricas y de otras organizaciones culturales. acerca de su alcance y de las posibilidades de constituir una alternativa al capitalismo; en ese sentido, Guillermo Campero (1987) acentuó la tensión entre las acciones de sobrevivencia y las acciones políticas, y Eugenio Tironi enfatizó el romanticismo y el conservadurismo que, a su juicio, impregnaba la acción comunitaria de los pobladores, descartando "una disposición particularmente favorable a la solidaridad grupal" (Tironi, 1987a: 14).

Con todo, el año 1983 constituyó un punto de quiebre en la historia de la lucha contra la Dictadura. A partir de mayo estallaron un conjunto de movilizaciones sociopolíticas conocidas como Jornadas de Protesta Nacional, con elevada presencia y protagonismo de pobladores, especialmente jóvenes, que permitieronvisibilizarlamagnitud deldescontento y concitaron la confluencia de amplios sectores sociales. En un primer momento, se sumaron en gran proporción las capas medias, aunque al tiempo que se sucedieron las protestas y ganaron en radicalidad y que, paralelamente, se fueron reorganizando los partidos políticos, y fue haciéndose evidente la distancia insalvable entre dos estrategias de salida de la Dictadura, ${ }^{5}$ su participación fluctuó y finalmente decayó. ${ }^{6}$ Este estallido social, esta "explosión de las mayorías" -como la nombraron Mario Garcés y

Una sustentada en la movilización permanente y acumulativa para derrocar a Pinochet; la otra, en la negociación entre élites transando algunas condiciones con el régimen militar.

6 Entonces, algunos sociólogos construyeron la tesis de la "rutinización" de la protesta, para indicar la esclerotización de las movilizaciones y su pérdida de eficacia -desde su perspectivaen la lucha antidictatorial. Con ello, justificaban la desafección que esa forma de acción suscitaba en las capas medias y su adhesión a la estrategia de las negociaciones cupulares. A su vez, presentaban a los sectores populares que persistían en las protestas como actores irracionales, volcados hacia formas políticas exclusivamente expresivas, no instrumentales. Véase Tironi (1987b: 67). 
Gonzalo de la Maza (1985)- remeció el escenario sociopolítico y forzó la apertura de espacios de democratización, aunque a la postre los sectores populares fueron desplazados por las cúpulas partidarias en la transición pactada.

Después de una década en la que parecía que nada se movía, la sociedad "perdió el miedo" -o lo controló-, y se abrió un ciclo de masivas y radicales movilizaciones, marchas, tomas, sublevaciones. Al calor de las Jornadas de Protesta Nacional se revitalizaron los estudios sobre pobladores, en particular, y movimientos sociales, en general, en el Chile dictatorial.

\section{La sociología de la negación: SUR y el movimiento de pobladores}

La sociología chilena ha estado fuertemente influenciada por los trabajos de Alain Touraine, cuya relación con América Latina, y particularmente con Chile, ha sido muy estrecha -personal y profesionalmente- desde mediados de los años cincuenta del siglo pasado. Para el sociólogo francés, un movimiento social consistía en "una acción colectiva organizada entablada contra un adversario social por la gestión de los medios a través de los cuales una sociedad actúa sobre sí misma y sobre sus relaciones con su entorno" (Touraine, 1982: 690). Su definición de movimiento social como un actor social central, que condensa las luchas sociales de un determinado tipo de sociedad y que disputa la definición de las orientaciones culturales (esto es, la historicidad o la capacidad de la sociedad de producirse a sí misma), constituyó el marco desde donde fueron interpretadas las protestas y movilizaciones desplegadas por los pobladores en Chile. Y, desde esa perspectiva, la conclusión "lógica" fue que no existían movimientos sociales en este país, porque el movimiento social no podía construirse jamás a partir de un sujeto (definido como) marginal y desde las prácticas anómicas y desviadas que lo caracterizaban (tal y como habían sido descritas las acciones de los pobladores). Los cientistas sociales chilenos, siguiendo al francés, afirmaron que "no hay movimientos sociales propiamente tales, esto es, acciones colectivas sistemáticas dirigidas contra un antagonista también social en un campo cultural e institucionalmente regulado" (Tironi 1986b: 15), aplicando taxativamente la definición antes citada. ${ }^{7}$ Quien mejor sintetizó la conclusión de este grupo de académicos fue, quizás, François Dubet ${ }^{8}$ :

\begin{abstract}
A causa de la exclusión y de su marginalidad, nunca los pobladores han podido constituir un real movimiento social, y es sólo de manera metafórica e ideológica que algunos han llegado a analizar las luchas de los marginales en los mismos términos que una acción de clases o e movimiento obrero. De la misma manera, nunca la lucha de los pobladores ha podido ser identificada como una lucha revolucionaria capaz de impulsar un cambio de tipo de sociedad (1987: 98)
\end{abstract}

Nótese, por un lado, la referencia explícita al movimiento obrero, como prototipo de movimiento social; $y$, por otro, la consideración reprobatoria, también categórica, de la lucha poblacional, negándole cualquier capacidad

Cabe señalar que esta conclusión de los discípulos chilenos de Touraine fue cuestionada por el mismísimo preceptor cuando, en el año 1987, participó en un seminario en Chile, argumentando que si bien no podía hablarse de movimientos sociales tal y como él los entendía, la sociología no podía conformarse con esa constatación, toda vez que la protesta y la organización popular eran también innegables: “¿Pero acaso no se puede decir nada más? Yo no lo creo [...] si no hay movimientos sociales, es porque existen pedazos, imágenes, elementos desocializados de tal movimiento. Aquí tenemos que ir un poco más allá" (Touraine 1987: 220).

8 Contraparte por el Cadis -Centro de Análisis e Intervención Sociológica (Cadis) de la École des Hautes Études en Sciences Sociales (Ehess)- del proyecto de investigación sobre los pobladores. 
de transformación de la sociedad. Desde esta perspectiva, más allá de las restricciones impuestas por el contexto dictatorial para la constitución de sujetos sociales autónomos ausencia de libertades políticas y de espacios democráticos, y débil o nula institucionalización de procedimientos para regular el conflicto-, los pobladores no podían constituir un movimiento social debido a sus propias limitaciones.

Los análisis de las acciones desplegadas por los pobladores nos permiten vislumbrar el concepto de movimiento social que subyace en esta perspectiva, a partir sobre todo, de lo que "les faltaba" o "les sobraba" a esos actores para constituirse en un "real" movimiento social. Es éste, sin duda, uno de aquellos casos en que los investigadores sociales proceden como el mítico posadero griego Procusto, que invitaba a los viajeros a acostarse en una cama y cortaba los pies de aquellos que sobresalían o, en el caso de que fueran más pequeños que el lecho, los descoyuntaba para estirarlos y hacerlos encajar en él. Así también, algunos sociólogos deformaron la realidad para embutirla en el concepto o bien cercenaron aquello que no cabía. En cualquier caso, el resultado de las operaciones anteriores es una insatisfactoria comprensión de la "realidad". Las conductas de los pobladores eran definidas como anómicas y desviadas, pudiendo expresarse su inadaptación o comportamiento antisocial de distintas maneras: ya fuera en su ensimismamiento o en su violencia desatada, en el retraimiento comunitario o en las acciones delincuenciales. Además, la anomia presuponía la falta de integración interna: algo que se manifestaba en la diversidad de expresiones que adoptaba la acción de los pobladores, y que conspiraba contra la unidad del movimiento. Los sociólogos de SUR identificaron cuatro "orientaciones" en su conducta:
Una reivindicativa, que razona en términos clasistas; otra populista, que se dirige al Estado en la defensa de los derechos ciudadanos; una tercera comunitaria, que busca la constitución de "un mundo de los pobladores"; $y$, por último, una orientación revolucionaria, que desea aprovechar las contradicciones para destruir al capitalismo (Tironi, 1987a: 15).

Las vías reivindicativa y populista apenas fueron consideradas, en sus análisis, por tratarse de las menos frecuentes y con menores condiciones de posibilidad, dadas las circunstancias impuestas por la Dictadura. ${ }^{9}$ Las otras, más extendidas, denotaban que los pobladores estaban demasiado imbuidos de nostalgias comunitarias o de ansias revolucionarias y, en cualquiera de los dos casos, esos sentimientos indicaban una desviación de la conducta adaptativa juzgada normal, a partir del mito de la modernización, que consideraba prototípico el proceso de transición desde las sociedades "arcaicas" a la moderna sociedad capitalista, experimentada por los países de Europa occidental. En ese sentido, la Dictadura podía ser leída -como hizo Tironi (1990: 32)- como un proceso modernizador "en lo económico, social y cultural", que armonizaba la realidad nacional con el proceso de reestructuración del patrón de acumulación iniciado en los países centrales del sistema capitalista desde mediados de los años setenta. Dicha mutación no respetaba, a juicio del sociólogo chileno, "ideologías, ni grados de desarrollo, ni posición geográfica” (ibid.: 29). Este juicio se sostiene a costa de hacer abstracción, por supuesto, de las violaciones de los derechos humanos y del embate represor de los derechos sociales y políticos. De acuerdo con la lectura modernizadora, las acciones de los pobladores expresaban su incapacidad de adaptarse a las

Para un análisis más detallado de la descripción de las "orientaciones" de las acciones de los pobladores véase Iglesias (2011: 46-56). 
nuevas condiciones -modernas- reforzando actitudes conservadoras o retrógradas.

Todo ello redundaba en la imposibilidad de que las iniciativas de los pobladores los constituyeran en un actor social, porque les restaba homogeneidad en sus rasgos constitutivos y en sus lógicas de acción. En contraste, lo que estos autores advertían era que el denominado movimiento de pobladores -que, a su parecer, tenía un "carácter fantasmagórico" (Tironi, 1986a), pues constituía más un deseo que una realidad- actuaba más como la expresión, a nivel poblacional, de "las distintas tendencias ideológicas nacionales que como intérprete de posiciones sociales homogéneas" de ese mundo (Tironi, 1987b: 74). En definitiva, Tironi concluyó que "las lógicas de acción que conviven en el movimiento de pobladores no logran pues constituirlo como un movimiento social" (id.). Y a la misma conclusión llegó Espinoza: "No se puede hablar de los pobladores como movimiento ni tampoco, todavía, se puede hablar de los pobladores como actor válido" (1983: 74, cursivas nuestras). El "desliz" del sociólogo no puede ser más revelador: la validez que le negaba a los pobladores aludía a su falta de legitimidad para participar en el diseño de la transición.

La pluralidad de "orientaciones" que hemos referido se plasmaba, asimismo, en la ausencia de programa político: los pobladores carecían de la suficiente claridad estratégica para concretar, en una propuesta formal, todas sus aspiraciones políticas, económicas y sociales. Por lo tanto, no existía, desde esta perspectiva, un proyecto de transformación social, sino huidas a la comunidad, demandas clientelistas al Estado o rebeliones vandálicas. Por eso, concluía Espinoza: "A los pobladores se les asigna un rol destacado en el proceso del derrocamiento de la Dictadura pero, en la conformación del proyecto hacia futuro, tienen un rol subordinado a la conducción de la clase obrera" (ibid.: 73). Esto es, en la difundida expresión de la época: hay protesta sin propuesta. De ahí la siguiente inferencia: "Tenemos acción, tenemos organización pero lo que falta es proyecto" (ibid.: 74).

La heterogeneidad de los pobladores y la ausencia de proyecto formalizado explican, a los ojos de los sociólogos de SUR, no sólo la inexistencia de un movimiento social propiamente tal, sino que las acciones desplegadas por ellos fueran vistas como teniendo un sentido totalmente opuesto (incluso "contrarrevolucionario"): "La crisis de la acción reivindicativa y los límites del comunitarismo desembocan en un fenómeno que corresponde bastante aproximadamente a lo que Touraine denomina a veces genéricamente como un 'antimovimiento social', cuya expresión más patente es la violencia" (Tironi, 1986b: 31). A decir del sociólogo chileno, la falta de homogeneidad en sus orientaciones y de la necesaria independencia de otros actores sociales y políticos -principalmente de los partidos políticos, pero también de la Iglesia y de las asociaciones de técnicos y educadores sociales-, para hacer valer sus intereses, su débil institucionalización, así como su explosiva acción y la alta dosis de violencia que acompañaba algunas desus protestas, hacían de lospobladores una amenaza para la recuperación democrática y ponían en peligro la ansiada negociación para la transición. Tironi llegó a sostener que "el miedo al Estado [...] que había logrado cohesionar a los más amplios grupos sociales en las primeras protestas, se revirtió en un miedo de la sociedad civil a sus propias tendencias auto-destructivas" (1987b: 67), lo cual podría convertirse "en un respaldo a una solución autoritaria" (ibid.: 65). En definitiva, la acción de los pobladores: 
Carece de la articulación necesaria como para que ellos puedan hacerse representar en la edificación de un orden democrático según una lógica concertacionista; su situación, por el contrario, se identifica más con la peligrosa situación de masas "en disponibilidad" para pasar de la apatía a una movilización de tipo milenarista, y viceversa (Tironi, 1986b, cursivas nuestras).

La referencia a las "masas" no es baladí; este concepto tiene en la trayectoria de las ciencias sociales una pesada carga de negatividad, pues suele negar el carácter racional de aquel colectivo al que se le aplica, y lo supone, en todo caso, moldeable desde "afuera", con arreglo a intereses externos. Una vez más se hacía hincapié en que los pobladores que resistían las agresiones del autoritarismo neoliberal no eran capaces de actuar de acuerdo a principios y fines que estructuraran una lógica interna, pues supuestamente carecían de tal lógica. De ahí la insistencia en el carácter anómico, desviado, retraído, apático, conformista, pre-político, impredecible y violento que se les atribuía. Y esa interpretación cimentó el camino para que las aspiraciones de los pobladores fueran desdeñadas y sus acciones, estigmatizadas y anatemizadas por quienes se consideraron capaces de edificar una sociedad "democrática". ${ }^{10}$

\footnotetext{
A pesar de la centralidad de esta mirada sociológica en el interior de la disciplina, no todos los sociólogos la compartieron; otros investigadores, además de llamar la atención sobre las tensiones presentes en la constitución de la identidad del actor poblacional, y acerca de las mutaciones experimentadas en los sectores asalariados, de corte tradicional, consideraron fundamentales los procesos de movilización y organización de los sectores populares de cara a la democratización de la sociedad; véase, entre otros, Valdés (1986). Más tarde, sociólogos como Moulian (1997) o Faletto (1998) se encargaron de hacer una lectura crítica de la deriva de la sociología hegemónica, que había negado y subordinado los movimientos sociales a las dinámicas de la política institucional, profesionalizante y tecnificista. Más recientemente, propuestas como las de Mayol (2012) constituyen un esfuerzo, desde la sociología, por dotar nuevamente de centralidad epistémica a los movimientos sociales, lo que es indicativo de la renovación crítica que ha venido experimentado la disciplina en los últimos años.
}

Si de alguna manera es expresión de la performatividad de las ciencias sociales el hecho de que la realidad nombrada se sienta reconocida en el nombre dado, la interpretación sociológica de las acciones colectivas de los pobladores, si bien hegemónica en la disciplina, generó resistencias entre ciertos sectores poblacionales que no se sintieron representados por la construcción teórica que de ellos se hacía y entre algunos cientistas sociales, que advirtieron, desde su particular perspectiva, una contradicción entre la realidad concreta y el "concreto de pensamiento", esto es, entre la realidad y la teoría. ${ }^{11}$ Los educadores populares y los historiadores sociales percibieron la irracionalidad de aquella construcción teórica de los movimientos sociales y propusieron otra muy distinta, como veremos a continuación.

\section{La afirmación del sujeto popular: La Nueva Historia}

El golpe de Estado de 1973 constituye un hecho traumático que afectó todas las dimensiones de la vida individual y social de las generaciones que lo sufrieron. En el plano teórico, la derrota de la "vía chilena al socialismo" supuso la necesidad de repensar los paradigmas desde los cuales se había examinado la transformación de la sociedad y, particularmente, la revolución; las distintas corrientes de pensamiento experimentaron procesos de renovación que discurrieron por cauces distintos y se concretaron en opciones teóricas y políticas muy diversas, incluso contradictorias. Sin embargo,

\footnotetext{
Para Marx el método científico correcto consiste en "elevarse de lo abstracto a lo concreto" (2007: 22), por medio de la síntesis de múltiples determinaciones abstractas. Por el camino del pensamiento se reproduce, un "concreto de pensamiento", que es distinto, no obstante, del concreto real, esto es, de la realidad.
} 
la mayor parte de esos esfuerzos compartió, al menos inicialmente, la revalorización de la investigación histórica, con el fin de acumular un mayor y mejor conocimiento de las condiciones concretas de la realidad chilena, toda vez que una de las críticas formuladas a la historiografía marxista precedente ponía de manifiesto su obsesión filosófica y su escaso conocimiento de la realidad nacional. ${ }^{12}$ De este modo, la ruptura histórica suscitó un "giro copernicano" (Garcés, 2003: 473) que, en el campo de la historiología, se expresó en el desarrollo de una nueva corriente, la Nueva Historia, cuyo principal signo distintivo ha sido reinstalar a los sectores populares en el centro del análisis sociohistórico, al reconocer su centralidad sociopolítica. ${ }^{13}$ De manera más general esta propuesta implica:

Elegir un punto de vista que interroga el pasado desde la experiencia de los sujetos de carne y hueso, y que reconoce en la experiencia concreta de los sujetos, individuales y colectivos, un principio fundamental de agenciamiento, de protagonismo, de historicidad. No hay historia sin sujeto y no hay sujetos sin historia, esta parece ser la premisa que organiza a la historia social (Garcés, 2003: 473).

Esta premisa deriva, efectivamente, de la crítica realizada por los historiadores a la historiografía prevaleciente hasta la década de los setenta tanto a la conservadora como a la marxista-, pero arraiga en la constatación empírica de la centralidad fáctica de los sectores populares en la resistencia y en la lucha antidictatorial,

12 Para una síntesis del "juicio" a la historiografía chilena realizado por los historiadores nacionales en la década de los ochenta, véanse las Actas del seminario de historia de Chile realizado en SUR, entre julio y noviembre de 1985 (VV.AA. 1986).

13 En la Nueva Historia convergen historiadores vinculados con distintas experiencias de búsqueda y reconstrucción de las identidades sociales populares, entre las que destacan los talleres de educación popular de la ONG ECO y las sesiones de trabajo del Encuentro de Jóvenes Historiadores. Para una descripción detallada de esa confluencia de procesos, véase Salazar (1985). expresada en las iniciativas populares de autogestión y, de manera incontestable, en las Jornadas de Protesta Nacional. Es la confluencia de aquellos dos procesos lo que determina "la entrada en la teoría política e histórica del 'sujeto social' en tanto que tal" (Salazar 1985: 102). De la generación historiográfica del ' 85 , como dio en llamarse a estos nuevos historiadores, retomaremos principalmente el trabajo de Gabriel Salazar, en particular en lo relativo a su discusión con los sociólogos negacionistas de SUR.

Cabría comenzar señalando que la ruptura epistémica que se expresó en la Nueva Historia implicó una serie de desplazamientos, abandonos y reafirmaciones. La primera de esas opciones estratégicas supuso desprenderse de cualquier atisbo de pretendida neutralidad valorativa en el quehacer científico. Una vez ratificadas las implicaciones políticas de toda ciencia social, el siguiente paso suponía explicitar desde dónde, con quién y para qué se construye conocimiento y, aquí, el historiador social adoptó decididamente el punto de vista de los sectores populares para, en palabras de Salazar, "construir una mirada teórica distinta a la que nos ha regido en la academia" (1985: 15), a cuyos ojos el movimiento de pobladores había carecido de una existencia real. En este caso, la reposición de los sectores populares como actores centrales de la historia vino de la mano de la modificación del locus epistémico. Partiendo de la premisa de que "no existe una posición privilegiada para conocer" (Salazar, 1999), la epistemología que subyace en la Nueva Historia supera la división canónica de la ciencia social moderna entre el investigador y su "objeto de estudio" -que pasa a ser considerado como "sujeto de acción" (Salazar, 1985: 18)-. Y se devela también la esterilidad $-y$ aun la falsedad- de la ciencia por la ciencia, buscando "una mirada teórica que se hace acción teórica" 
(ibid.: 15); esto es, que entiende todo saber (praxis cognitiva) como un momento de la praxis transformadora, en una simbiosis imprescindible y fecunda.

Frente a una concepción de los sectores explotados, dominados y marginados del sistema, en términos predominantemente de lo que en ellos está negado, Salazar recupera la visión estrictamente marxiana al subrayar el aspecto positivo, "la posición o autoafirmación y autoconfirmación que va implícita en la negación de la negación" (Marx, 1962: 110), porque el "ser" se afirma a sí mismo al negar lo que lo niega, y en esa lucha ya están presentes -en proceso incesante de construcción- ${ }^{14}$ las identidades y los proyectos de los sectores populares. Así, Salazar propone una mirada del movimiento popular centrada "en la afirmación de la afirmación. O sea: centrada en 'lo propio' (no en lo ajeno o en el enemigo), en la 'identidad' (no en la alienación), y en el 'poder' que emana de la solidaridad y la mirada colectiva" (Salazar, 1985: 17). Por esta vía, el análisis de los movimientos sociales se sustenta no tanto en la historia de miserias y carencias del "bajo pueblo", sino sobre todo en los aspectos positivos -afirmativos- que dichos sectores potencian para reproducir su vida. Por ende, sobresalen sus prácticas de solidaridad, de

\footnotetext{
14 Queremos apuntar nuestra discrepancia, en este punto, con el historiador Sergio Grez, quien recrimina a la perspectiva salazariana "no aspirar a la politización plena y continuar, en cambio, una rebeldía que de acuerdo con esa opción debiera ser eterna" (Grez, 2005: 24). Efectivamente, las implicaciones profundas de la renovación historiológica presuponen una comprensión del movimiento social como una lucha perenne por mayores cuotas de humanización; y, por otra parte, entrañan la superación de la escisión excluyente entre lo social y lo político, al no identificar la "politización plena" exclusivamente con la incorporación a las instituciones y disputas estatales. Lo contrario supone ansiar proyectos totalizadores que supuestamente conjuran los conflictos sociales; aspiración que ya concretó el mal llamado "socialismo real", con efectos desastrosos.
}

compañerismo, de ayuda mutua, de fraternidad; experiencias que cimentan su identidad y aseguran su sobrevivencia.

Loanterior no significa que el movimiento popular, o el pueblo, sea pensado exclusivamente a partir de sus rasgos y prácticas afirmativas; ${ }^{15}$ al contrario, conviven en su seno esas cualidades con las tendencias a la asimilación, al acomodo y a la subalternización. El proceso de afirmación "lleva, por tanto, en su entraña su contraposición" (Marx, 1962: 110). Quizás el reconocimiento más franco de ese carácter contradictorio del pueblo sea el que realizara Salazar en su tesis doctoral al referirse a sus vivencias personales: "Mi infancia se pobló densamente de las imágenes proyectadas por la sociedad 'de la esquina': hombres, mujeres, niños, perros, harapos, tarros, hambre, frío, riñas, heridas, alcohol, pero sobre todo, calor humano. Calor humano que emanaban esos hombres y mujeres cada vez que percibían cerca de ellos el aliento inconfundible de la solidaridad" (1985: 19). Es esta identidad solidaria la que el historiador asume como médula de su labor investigativa. $Y$ es en virtud de ello que el movimiento popular se constituye como el reducto desde donde pensar la transformación del sistema, ${ }^{16}$ pues es expresión de lo que está

15 Como ha pretendido una lectura superficial y a menudo (mal) intencionada de los trabajos de Salazar, con el propósito de atribuir a su perspectiva un "reduccionismo esencialista". Por el contrario Salazar advierte: "La sinergia solidaria e identitaria interna de los rotos no podía, por tanto, ser estudiada de modo aislado. Como un fenómeno histórico químicamente puro" (2003: 21). Sobre la formulación más explícita de la crítica y la respuesta del propio historiador, veáse el prefacio a la segunda edición de su libro La violencia política popular en las "Grandes Alamedas". La violencia en Chile 1947-1987 (Una perspectiva histórico popular) (Salazar, 2006: 5-24). Otro cuestionamiento en el mismo sentido pero desde la propia historia social, en Grez (2005).

16 O de otra forma: "El movimiento popular posee, casi en términos de unción monopólica, el carisma de ser el arranque social de una sociedad humanamente mejor (no tecnológicamente superior, tan solo)" (Salazar, 2006: 310) 
negado por él y, a la vez, afirmación de otro mundo posible, ya que "comporta principios sociales alternativos y eventualmente superiores de reintegración y redemocratización de la sociedad" (Salazar, 2006: 307). Esta premisa queda más claramente formulada en la siguiente definición de movimiento social:

\begin{abstract}
El 'movimiento social' no es más que la sociedad (especialmente la popular) en su estado puro; es decir, en el gerundio de la creación social de sí misma. Es por ello que el 'movimiento social' tiene su origen en el estrato del "bajo pueblo". Y, principalmente aquí. Puesto que, normalmente, el "bajo pueblo" siente la necesidad de la 'recreación permanente' como un imperativo categórico. Por lo tanto, en ese sentido específico, el 'movimiento social' no admite la anomia como una parte de sí, ya que la anomia está siempre donde no está el pueblo (Salazar, 1986: 118).
\end{abstract}

No cabe duda de que, desde esta perspectiva, es precisamente la resistencia de los pobladores y su capacidad socio-constructiva lo que resulta de particular interés, desechando la atribución de tendencias auto-destructivas per se; y, por ende, su interpretación de las prácticas comunitarias y de las protestas de los ochenta debía ser radicalmente distinta de la que defendieron los sociólogos a los que nos hemos referido en el apartado anterior. De entrada, los historiadores sociales evidenciaron el trasfondo eurocéntrico y elitista de los análisis de los pobladores que contraponen la barbarie y la irracionalidad, a la modernidad y la civilización (Salazar, 2012: 154). Y denunciaron, a su vez, la estrechez del concepto de movimiento social al ser reducido, de manera más o menos explícita, al de movimiento obrero, con las consecuencias políticas que dicha simplificación comporta. Por el contrario, Salazar sostiene:

Que el proletariado industrial sea la identidad social "ideal" -en tanto estrato masivamente dependiente de un salario- para situar los objetivos populares de liberación, no significa que los que no son dependientes de un salario carezcan de identidad social y de capacidad para "entrar" en la lucha de clases. En un país como Chile, tan coaccionado por "desviaciones desestructurantes", los "sectores independientes" copan la mayor parte del "polo popular" de la lucha. Y por su independencia, acaso, se hallan eventualmente más "libres" para entrar en la lucha. Pues, para la mayoría de los casos, esa independencia "consiste" en la extrema pobreza, la máxima opresión y la suprema desviación, o sea, en el fondo "definitorio" de lo que es en sí mismo el "bajo pueblo" (1986: 116).

Tenemos, pues, que "en la historia misma, el sujeto popular es más ancho y abigarrado que la clase proletaria en sentido estructural estricto" (Salazar, 2006: 150). Pero ello no obsta para que el movimiento popular haya tenido una participación decidida en numerosos momentos de la historia de Chile y, particularmente, en los ochenta, cuando lospobladores se constituyeron "en el sector social más activo y movilizado, contribuyendo de modo muy significativo a la recuperación de la democracia" (Garcés, 2013: 76). El fracaso de la opción movilizadora -de la política de rebelión popular de masas, según la formulación del Partido Comunista de Chile- en el derrocamiento de la Dictadura no determina su existencia, ni la profundidad de su propuesta democratizadora, pues el movimiento popular "ni se origina ni se agota en el derrocamiento de generales o presidentes impopulares, ni consiste en una mera táctica" (Salazar, 2006: 305). Muy por el contrario, el examen de las organizaciones económico-populares $y$, en general, de la asociatividad desplegada por el movimiento de pobladores revela la hondura y la proyección -el carácter estratégico- de sus motivaciones. Con todo, para el movimiento popular el balance general de las Jornadas de Protesta Nacional es agridulce:

De un lado, con ellas abrió una decisiva brecha psicológica y política en el flanco popular de la dictadura; pero, de otro, perdió la batalla de 'la transición' en el segundo 
frente (el de la negociación), enceguecido por la inercia VPP [violencia política popular], empantanado por las tácticas distractoras del estamento militar, desarmado por la compulsión parlamentarista de su aliado mesocrático, y formalmente superado en los mismos umbrales de la eventual 'democracia' (ibíd.: 304)

Salazar no desconoce la heterogeneidad del movimiento popular y tampoco niega sus limitaciones para explicitar y formalizar los elementos y las propuestas que laten en sus prácticas sociopolíticas; en ese sentido, reconoce su dificultad para "pasar fluidamente de la protesta a la propuesta" (ibid.: 306). Pero no considera que esas características anulen su historicidad y el potencial para desplegarse como actor sociopolítico. En ese sentido, advierte de la necesidad de analizar a los sujetos de "carne y hueso", prescindiendo de categorías abstractas que buscan hacer encajar la realidad en la teoría, pues la base social -en movimiento"no podrá ser detectada ni valorada, si para ello se utilizan y se aplican categorías sistémicas de definición y observación" (ibíd.: 169). Y esto porque "estrictamente, se trata de un sujeto predominantemente desestructurado que se constituye como tal sobre todo en la acción y en el movimiento" (ibíd.). Es, a su juicio, este carácter móvil, inestable, cambiante, de las identidades sociales frente a la naturaleza relativamente fija de la estratificación estructural el que dificulta la aprehensión de sus acciones por parte de una teoría ciega al devenir histórico. Por lo tanto, el movimiento social es visto como un "proceso lento, cualitativo, diverso, amplio, de continuidad y ruptura, a partir de la subjetividad popular" (Agurto y Milos, 1983: 8). Con ello, pierde centralidad en la reflexión el peso de las estructuras, la influencia de las minorías lúcidas, de las vanguardias, la linealidad de los procesos; y gana terreno la complejidad del sujeto, la pluralidad de los actores, el despliegue de las contradicciones, las abigarradas vías de construcción de la subjetividad popular.

Por otra parte, la diferente interpretación de las acciones de los pobladores se explica por una concepción distinta de la política. ${ }^{17}$ Frente a lo que Salazar define, acertadamente, como una propuesta de modernidad neoliberal y una lectura estatalista de la política, que identifica esta dimensión de la vida social con una esfera auto-centrada circunscrita al Parlamento y a los partidos políticos, y la representación con la vía primordial de constitución de los sujetos políticos, la Nueva Historia plantea una forma distinta, popular, de hacer política, que se caracteriza por la 'tendencia del 'bajo pueblo' a territorializar, concretizar y socializar la acción directa. Es decir, a hacer política privilegiando la 'acción directa'" (Salazar, 2006: 309). A su juicio, esa política popular adolece de un déficit de formalización, explicable porque el movimiento popular ha carecido históricamente del entrenamiento y de la experiencia necesarios (ibid.: 306); y también por "la persistente acrimonia y el desinterés ejercitados por la alta intelectualidad chilena frente a las necesidades teóricas específicas del movimiento popular" (ibid.: 307).

\footnotetext{
Aspecto sustancial también de las controversias al interior de la historia social. Nos referimos explícitamente a la discusión en torno a "la historia social con o sin política incluida", cuestión que formulara el historiador Sergio Grez (2005) y de la que ya hemos hecho mención. Concretamente, Grez acusa el hecho de que en la perspectiva salazariana la dimensión política sea dejada de lado y advierte en esa historiografía la naturalización de lo popular y la idealización de los actores sociales aun con sus cuotas de "barbarie" e "irracionalidad". A nuestro juicio esta crítica se fundamenta en una concepción tradicional, liberal, de la política, que no permite trabajar con los actores tradicionalmente excluidos y dominados, pues sólo considera "políticos" a los movimientos que enfocan su acción desde y hacia la esfera institucional de la política y la disputa estatal, desconociendo o desvalorizando las acciones de construcción y de proyección del movimiento popular en otros espacios de sociabilidad. Un análisis más profundo de este debate en Iglesias (2015).
} 
Ese desabrimiento que Salazar atribuye a una parte del pensamiento social estaría dado por la adhesión alos postulados modernos (sistémicos) en su comprensión de la sociedad y de los actores sociopolíticos, y por el compromiso con el régimen económico y político neoliberal en sus formas esenciales, que en la década de los ochenta se expresó en el apego a la salida pactada de la Dictadura, presentada como la única opción viable y racional, para lo cual resultaba imprescindible "negar teóricamente y bloquear políticamente el protagonismo histórico del movimiento popular" (ibid.: 306).

En definitiva, para la Nueva Historia, "los protagonistas de los hechos de VPP han levantado y echado a andar un movimiento social que no tiene sistematicidad (ni lealtad al sistema, ni orden sistemático, ni racionalidad funcional), pero sí tenacidad del proyecto, y en consecuencia, lógica de historia, que apunta (solo apunta) a construir un orden nuevo" (Salazar, 2006: 149). Esta perspectiva contribuye a visibilizar y apreciar un movimiento social que no había sido suficientemente estudiado ni valorado por la teoría social, específicamente por los sociólogos negacionistas -a los que Salazar denomina "Touraine's Boys" (2012: 97)-, cuyos trabajos dan cuenta de una mirada miope o prejuiciada que pre-conceptúa la realidad, clasifica y fija a los actores sociales y descarta todo aquello que no tenga cabida dentro de los estrechos márgenes de conceptos "importados" y absolutamente "cerrados". Frente a la negación de los movimientos sociales y la interpretación desdeñosa de las luchas de los pobladores, la Nueva Historia emprende un esfuerzo teórico honesto por comprender los movimientos sociales reales que han emergido en Chile, trabajando "una perspectiva complementaria que, al día de hoy, parece ser indispensable" (Salazar, 1985: 18).

\section{Consideraciones finales}

Casi tres décadas después del reventón popular de las Jornadas de Protesta Nacional, el movimiento estudiantil remeció la sociedad chilena, protagonizando multitudinarias marchas y diversas e innovadoras formas de protesta, dinamizando un proceso amplio y heterogéneo de lucha social y marcando por largo tiempo la agenda política del país. En ese contexto, uno de los ideólogos de la transición, pronunció el siguiente veredicto: "Las marchas se han vuelto una performance rutinaria, con un corolario de violencia que reflejan la elección de un 'método de lucha', una expresión de acción irracional-anárquica y una manifestación de jóvenes desintegrados que utilizan la calle como escenario para la anomia" (Brunner, 2012: 10, cursivas nuestras). La reiteración de los mismos atributos para caracterizar al movimiento estudiantil que antes sirvieron para descalificar al movimiento de pobladores, no puede ser sino signo del anquilosamiento de una sociología que decretó su propio ocaso (Brunner, 1998). A la luz de lo anterior, no cabe duda de que la última afirmación de Salazar sigue más vigente que nunca: resulta indispensable una perspectiva de análisis de las luchas sociopolíticas capaz de superar los diagnósticos apriorísticos y comprender las dinámicas profundas de las contradicciones y de los antagonismos que atraviesan el cuerpo social y los actores en lucha.

La breve síntesis realizada aquí de los presupuestos epistemológicos que subyacen en el análisis del movimiento de pobladores reedita algunos de los nudos gordianos del examen de los movimientos sociales y arroja luz sobre problemas y debates de máxima actualidad. La negación de la existencia de un movimiento de pobladores pone de manifiesto cómo el concepto 
de movimiento social se convirtió, de algún modo, en un compartimento estanco que, tal y como sucediera anteriormente con la categoría de "clase obrera", dificultó más la comprensión de las particularidades de la realidad chilena, que lo que ayudó a su esclarecimiento: poco se avanzó en el terreno del conocimiento con decir que "no hubo, no hay, no habrá" (Touraine, 1987: 218-219) movimientos sociales en Chile. La rigidez del enfoque sociológico revisado se tradujo en una actitud de reproche hacia la realidad, ante la inadecuación de los hechos a la teoría, debido a aquello que le faltaba para constituir un "verdadero" o "real" movimiento social. La heterogeneidad presente en el sector poblacional y la diversidad característica del actor poblacional fueron interpretadas, desde esta perspectiva, como un impedimento para la constitución de movimientos sociales y, por ende, de prácticas con un potencial transformador, en un sentido positivo, de la sociedad. La unidad fue pensada como uniformidad, homogeneidad de características sociales, de tácticas de acción, de proyectos de futuro; y además fue considerada un punto de partida. Por otra parte, la política fue concebida en forma absolutamente restringida, como la política partidaria y estatal; por ende, las conductas y actitudes que no apuntaban en ese sentido, no eran políticas. A su vez, lo social sin la política -así entendida-, parecía pura expresividad, irracionalidad, emociones primarias, inviabilidad. Hay un sesgo en esta mirada hacia lo dado, lo ya definido, lo estable, que trata de captar en un momento las características estructurales, abstractas y generales, de un "objeto" y fijarlo de acuerdo con las categorías construidas ex ante. Y también aboga por una idea de la transformación en la que es necesario definir de antemano un proyecto global de una sociedad distinta (determinar en el presente cómo será en todos sus aspectos la futura sociedad).
El contrapunto argumentativo procede de la Nueva Historia, que tiende a pensar la transformación como un proceso de largo aliento y visibiliza los vaivenes de las experiencias de lucha. El carácter procesual y la perspectiva no lineal de la historia que rescata esta mirada historiológica, suponeconcebirlaunidadnocomo homogeneidad, ni siquiera como hegemonía, sino como complementariedad, encontrando los elementos comunes que permiten la comunicación, y el encuentro, entre los distintos movimientos sociales. Así entendida, la unidad es un fin -y no un principio-, aunque siempre reversible y mudable. Ello supone abandonar también la visión (y la ambición) totalizante de las luchas. Además, la unidad de los procesos antagonistas no excluye el reconocimiento de las particularidades. Valorar lo diverso, lo plural, lo distintivo, esto es, concebirlo como algo que suma, en lugar de restar, como una condición que enriquece los procesos de transformación, que posibilita complementarse mejor y abrir distintas vías de revolución, permite avanzar en un acercamiento más complejo e integral de los problemas sociales. Desde esta perspectiva, el proyecto político no se expresa exclusiva o necesariamente en la propuesta formal de un número determinado de principios programáticos; el proyecto es una constelación de propuestas -más o menos explícitas- que van configurando una sociabilidad distinta, pero siempre en tensión. Obviamente la imagen propuesta de la revolución social resulta un poco más compleja, y quizás un punto menos romántica, que la tradicional, pero quizás también más factible y fructífera.

El desafío en el que avanza la Nueva Historia y al que no debe renunciar una sociología crítica, estriba a nuestro parecer en la posibilidad de comprender los movimientos sociales como 
entidades-procesos complejos, diversos, contradictorios, abiertos y cambiantes; y las dinámicas de transformación de la sociedad a partir del despliegue de posibilidades que se configuran en las propias luchas, en la confrontación de propuestas, en el aprendizaje continuo y en el ensayo incesante de formas diversas de apropiarse de la capacidad de construir mundos alternativos. En definitiva, en reconocer que la posibilidad de un mundo justo y solidario se funda en la afirmación de aquello que afirma ese tipo de valores y relaciones, o de otra manera, en la negación de lo que lo niega.

\section{Bibliografía}

Agurto, Irene; Milos, Pedro. 1983. "Momento político y protagonismo popular". Educación y Solidaridad 4: 5-10.

Brunner, José Joaquín. 1998. "Sobre el crepúsculo de la sociología y el comienzo de otras narrativas". Revista de Estudios Sociales 1. En línea, disponible en: http://www.redalyc.org/ articulo.oa?id=81511376029 (visitado 25 de enero de 2015). . 2012. "El movimiento estudiantil entró en un túnel del que no puede salir". La Tercera, 11 de agosto, sección Reportajes, 10-11.

Butler, Judith. 2004. "Performative acts and gender constitution. An essay in phenomenology and feminist theory". The Performance Studies Reader. Bial, Henry (ed.). Nueva York: Routledge. 154-166.

Camacho, Daniel; Menjívar, Rafael (coords.). 1989. Los movimientos populares en América Latina. México: Universidad de las Naciones Unidas / Siglo XXI.

Campero, Guillermo. 1986. "Luchas y movimientos sociales en la crisis: ¿Se constituyen movimientos sociales en Chile?: Una introducción al debate". Los movimientos sociales y la lucha democrática en Chile. VV. AA. Santiago: Clacso/UNU. 9-19.

. 1987. Entre la sobrevivencia y la acción política. Las organizaciones de pobladores en Santiago. Santiago: ILET.

Dubet, François. 1987. "Las conductas marginales de los jóvenes pobladores". Proposiciones 14: 94-100.

Espinoza, Vicente. 1983. "Protesta, movilización y construcción de movimiento en el sector poblacional". Educación y Solidaridad 4: 65-75.

Faletto, Enzo. 1998. “¿Crisis de la sociología?”. Némesis. Revista de Estudiantes de Sociología de la Universidad de Chile 1: 20-25.

Garcés, Mario. 2003. "Reseña de Gabriel Salazar y Julio Pinto. Historia Contemporánea de Chile, Volúmenes I al V, Lom Ediciones, Santiago de Chile, 1999-2002". Historia 36: 470-473. 2004. "Los movimientos sociales populares y la izquierda chilena en la Unidad Popular y su respuesta frente al golpe de Estado de septiembre de 1973". En línea, disponible en: http://www.archivochile.com/Ideas_Autores/garcesm/ garcesm0004.pdf (visitado 25 de enero de 2015)

2013. "Las luchas urbanas en Chile en el último tercio del siglo XX". Trashumante. Revista Americana de Historia Social 1: 74-95.

y De la Maza, Gonzalo. 1985. La explosión de las mayorías. Protesta Nacional 1983-1984. Santiago: ECO.

Grez, Sergio. 2005. "Escribir la historia de los sectores populares. ¿Con o sin la política incluida? A propósito de dos miradas a la historia social (Chile, siglo XIX)". Política 44: 17-31.

Guillaudat, Patrick; Mouterde, Pierre. 1998. Los movimientos sociales en Chile. 1973-1993. Santiago: LOM.

Iglesias, Mónica. 2011. Rompiendo el cerco. El movimiento de pobladores contra la Dictadura. Santiago: RUCh.

2015. "La construcción (teórica) de los movimientos sociales en Chile. El campo de batalla de la Sociología (Política) y la Nueva Historia (Social)". Tesis para optar al grado de Doctora en Estudios Latinoamericanos. Posgrado en Estudios Latinoamericanos, Universidad Nacional Autónoma de México.

Marx, Karl. 1962. "Manuscritos económico-filosóficos de 1844". Escritos económicos varios (traducción de Wenceslao Roces). Marx, Karl; Engels, Friedrich. México: Grijalbo: 25-125. 2007. "El método de la economía política". Elementos fundamentales para la crítica de la economía política (Grundrisse) 1857-1858. Vol. I. Marx, Karl. México: Siglo XXI: 20-30.

Mayol, Alberto. 2012. No al lucro. De la crisis del modelo a la nueva era política. Santiago: Debate.

Moulian, Tomás. 1997. Chile Actual: Anatomía de un mito. Santiago: LOM / Arcis.

Merton, Robert K. 1964. Teoría y estructura social. México: FCE.

Razeto, Luis. 1986. Economía popular de solidaridad. Identidad y proyecto en una versión integradora. Santiago: Área Pastoral Social de la Conferencia Episcopal de Chile, Programa de Economía del Trabajo.

Salazar, Gabriel. 1985. Labradores, Peones y Proletarios. Formación y crisis de la sociedad popular chilena del siglo XIX. Santiago: SUR. 
1986. “Delageneración chilena del '68: ¿Omnipotencia, anomia, movimiento social?". Proposiciones 12: 96-118.

1999. "Sobre unas críticas indirectas a la Historia Contemporánea de Chile". El Mercurio, 6 de junio, sección Artes y Letras.

2003. "Historia popular, Chile, siglo XIX: Una experiencia teórica y metodológica". La historia desde abajo y desde adentro. Salazar, Gabriel. Santiago: Facultad de Artes, Universidad de Chile, Departamento de Teoría de las Artes. 9-28. 2006. La violencia política popular en las "Grandes

Alamedas". La violencia en Chile 1947-1987 (Una perspectiva histórico popular). Santiago: LOM.

2012. Movimientos sociales en Chile. Trayectoria histórica y proyección política. Santiago: Uqbar.

Tironi, Eugenio. 1986a. "El fantasma de los pobladores". Estudios Sociológicos 12: 391-397.

1986b. "Para una sociología de la decadencia".
Proposiciones 12: 12-16.

. 1987a. "Introducción". Proposiciones 14: 9-20.

1987b. "Pobladores e integración social".

Proposiciones 14: 64-84.

1990. "Crisis, desintegración y modernización".

Proposiciones 18: 16-42.

Touraine, Alain. 1982. "Reacciones antinucleares o movimiento antinuclear". Revista Mexicana de Sociología 44/2: 689-701.

. 1987. "Conclusión: La centralidad de los marginales".

Proposiciones 14: 214-224.

México: FCE.

2000. ¿Podremos vivir juntos? Iguales y diferentes.

Valdés, Teresa. 1986. "El movimiento poblacional: la recomposición de las solidaridades sociales". Documento de Trabajo 283, Programa Flacso-Chile.

W.AA. 1986. "Historiografía chilena: Balance y perspectivas. Actas del seminario de historia de Chile". Proposiciones 12: 157-170. 